University of Wollongong

Research Online

Faculty of Engineering and Information

Faculty of Engineering and Information

Sciences - Papers: Part A

Sciences

$1-1-2013$

\title{
Multi-objective reactive power support from wind farms for network performance enhancement
}

Lasantha Meegahapola

University of Wollongong, lasantha.meegahapola@rmit.edu.au

Brendan Fox

Queen's University of Belfast, b.fox@ee.qub.ac.uk

Tim Littler

Queen's University of Belfast, t.littler@ee.qub.ac.uk

Damian Flynn

University College Dublin

Follow this and additional works at: https://ro.uow.edu.au/eispapers

Part of the Engineering Commons, and the Science and Technology Studies Commons

Research Online is the open access institutional repository for the University of Wollongong. For further information contact the UOW Library: research-pubs@uow.edu.au 


\title{
Multi-objective reactive power support from wind farms for network performance enhancement
}

\begin{abstract}
This paper examines the ability of the doubly fed induction generator (DFIG) to deliver multiple reactive power objectives during variable wind conditions. The reactive power requirement is decomposed based on various control objectives (e.g. power factor control, voltage control, loss minimisation, and flicker mitigation) defined around different time frames (i.e. seconds, minutes, and hourly), and the control reference is generated by aggregating the individual reactive power requirement for each control strategy. A novel coordinated controller is implemented for the rotor-side converter and the grid-side converter considering their capability curves and illustrating that it can effectively utilise the aggregated DFIG reactive power capability for system performance enhancement. The performance of the multi-objective strategy is examined for a range of wind and network conditions, and it is shown that for the majority of the scenarios, more than $92 \%$ of the main control objective can be achieved while introducing the integrated flicker control scheme with the main reactive power control scheme. Therefore, optimal control coordination across the different control strategies can maximise the availability of ancillary services from DFIG-based wind farms without additional dynamic reactive power devices being installed in power networks.
\end{abstract}

\section{Keywords}

performance, network, farms, wind, enhancement, support, multi, power, reactive, objective

\section{Disciplines}

Engineering | Science and Technology Studies

\section{Publication Details}

L. Meegahapola, B. Fox, T. Littler \& D. Flynn, "Multi-objective reactive power support from wind farms for network performance enhancement," European Transactions on Electrical Power, vol. 23, (1) pp. 135-150, 2013. 


\title{
Multi-Objective Reactive Power Support from Wind Farms for Network Performance Enhancement
}

\author{
Lasantha Meegahapola ${ }^{1}$, Brendan Fox ${ }^{2}$, Tim Littler ${ }^{2}$, Damian Flynn ${ }^{3}$ \\ ${ }^{1}$ University of Wollongong, Wollongong, 2500, Australia \\ ${ }^{2}$ The Queen's University of Belfast, School of Electronics, Electrical Engineering \\ and Computer Science, Belfast BT9 5AH, UK \\ ${ }^{3}$ University College Dublin, Belfield, Dublin 4, Ireland
}

\begin{abstract}
This paper examines the ability of the doubly-fed induction generator (DFIG) to deliver multiple reactive power objectives during variable wind conditions. The reactive power requirement is decomposed based on various control objectives (e.g. power factor control, voltage control, loss minimisation, and flicker mitigation) defined around different time frames (i.e. seconds, minutes, and hourly) and the control reference is generated by aggregating the individual reactive power requirement for each control strategy. A novel coordinated controller is implemented for the rotor-side converter (RSC) and the grid-side converter (GSC) considering their capability curves and illustrating that it can effectively utilise the aggregated DFIG reactive power capability for system performance enhancement. The performance of the multi-objective strategy is examined for a range of wind and network conditions and it is shown that for the majority of the scenarios more than $92 \%$ of the main control objective can be achieved while introducing the integrated flicker control scheme with the main reactive power control scheme. Therefore, optimal control coordination across the different control strategies can maximise the availability of ancillary services from DFIG based wind farms without additional dynamic reactive power devices being installed in power networks.
\end{abstract}

\section{Key Words}

Capability curve, doubly-fed induction generator (DFIG), flicker mitigation, power factor control, reactive power dispatch, voltage control.

\section{Introduction}

Reactive power control has emerged as one of the main control issues faced by power utilities due to increased renewable power penetration in electrical networks. Voltage variations due to variable wind generation, and dynamic voltage security are some of the major challenges faced by distribution network operators (DNOs) due to insufficient reactive power support for active distribution networks [1-2]. In addition, transmission system operators (TSOs) have also experienced major issues in terms of acquiring adequate reactive power resources to maintain network stability and economic operation due to the displacement of conventional generation. One solution would be to commission additional reactive power compensation sources (e.g. capacitor banks, static VAr compensators (SVCs), static-synchronous 
compensators (STATCOMs)) to supply the reactive power demand in the system. However, from the utility and the wind farm developers' perspective it is more economical to optimise existing assets to deliver enhanced reactive power performance to support network requirements. Economic and technical studies have previously been performed on wind farm reactive power capability for ancillary service markets [3-4], potentially leading to future system operators dispatching reactive power from wind farms to deliver system requirements.

A number of reactive power control strategies have also been proposed by both academia and industry to utilise the inherent reactive power capability of power electronics based wind generators (e.g. doubly-fed induction generator (DFIG) and full converter wind generator (FCWG)) for power system steady-state and dynamic performance enhancement [5-13]. In [5-8] the reactive power capability of variable speed wind generators was used to enhance voltage and transient stability during grid disturbances. Furthermore, different coordinated reactive power control configurations for the rotor-side and grid-side converters were presented in [6] for voltage control purposes. However, these studies didn't explicitly consider the reactive power capability curve of a DFIG during steady-state and dynamic operating conditions.

The inherent reactive power capability of a DFIG has been further studied for transmission loss reduction during variable wind conditions [9-11], although the full capability of the DFIG system (i.e. both the rotor-side converter (RSC) and the grid-side converter (GSC)) was not utilised. A study presented in [10] advocates that the DFIG's reactive power capability can be utilised for system loss reduction, voltage profile improvement and damping of oscillations, considering the reactive power capability curve of the DFIG-RSC only. Furthermore, reactive power control strategies have also been proposed for flicker mitigation during variable wind conditions [12-13].

The reactive power control time frame for the aforementioned strategies varies from milliseconds to hours based on the reactive power requirements of the network. As an example, reactive power dispatch for system loss reduction is implemented based on the system demand and wind generation, and hence the control reference is updated on a half-hour or hourly basis by the system operator [4]. The power factor and voltage control schemes are longer-term strategies, and hence the control reference is determined based on the voltage or power factor requirement stipulated by the grid code standards [14-15]. During grid faults additional reactive power control strategies are implemented to support local voltage to improve the voltage stability of the local network and obtain a wind generator fault-ride through (FRT) improvement. The FRT strategies are typically limited to milliseconds to seconds [5-8]. Moreover, the reactive power reference for flicker emission is determined based on the wind power variation over a short time interval [12].

Even though individual reactive power control strategies are developed for different control time frames, limited focus has been placed on delivering multiple reactive power objectives for system performance enhancement. Therefore, the main emphasis of this paper is to provide a comprehensive analysis of the reactive power demand required from various control schemes and to assess the capability of DFIGs to 
deliver multiple control objectives under different wind and network conditions. The control performance of the proposed schemes is verified using wind power data measured at an actual DFIG wind farm and simulations were performed using the DIgSILENT Power Factory software package.

This paper is organised as follows: the DFIG model validation and the test system are presented in Section 2. The DFIG reactive power capability curves and the novel coordinated reactive power control scheme are outlined in Section 3. The multi-objective reactive power control strategies and their performance comparison are presented in Section 4. The dynamic performance of the multi-objective strategies is analysed for a range of wind (e.g. mean wind speeds and turbulence intensities) and network conditions (e.g. short-circuit ratio (SCR) and $\mathrm{X} / \mathrm{R}$ ratios) in Section 5. A discussion is presented in Section 6 while the conclusions of the study are summarised in Section 7.

\section{DFIG Model Validation and Test Network}

The wind farm considered in this study is located in Northern Ireland (NI), and is based on the GE 1.5 MW DFIG wind generator [17]. The total installed capacity of the wind farm is $19.5 \mathrm{MW}(13 \times 1.5$ MW). The power output of the wind farm was determined from captured data (i.e. phase voltage, current and power factor angle) using a GPS synchronised data measurement system installed at the wind farm substation. The average wind speed at the wind farm location was derived based on the following assumptions:

- All wind generators in the wind farm are online

- Wind speed distribution is uniform across the wind farm

A schematic diagram of the DFIG simulation model is shown in Figure 1. A function approximation was derived to obtain the wind speed from the measured electrical power output of the wind farm based on the GE 1.5 MW power vs. wind speed curve [16]. The DFIG can be realised by a wound rotor induction generator (WRIG) and a back-to-back converter system. The DFIG control model was designed based on the GE 1.5 MW wind generator [16] while the WRIG parameters are based on a typical induction generator (see Appendix). Theoretically, a back-to-back converter rated at $30 \%$ of the machine rating is sufficient for the full operating range (0.7-1.2 pu speed) of the DFIG. However, most commercial designs allow an additional capacity, and hence the DFIG simulation model was designed with a $50 \%$ back-to-back converter.

A test system was developed (see Figure 2) in DIgSILENT power factory using an aggregated wind farm model which was connected to the transmission system by a $33 \mathrm{kV}, 10 \mathrm{~km}$ long distribution feeder (X/R =1). The short-circuit apparent power at the grid connection point is 2500 MVA which ultimately results in a short-circuit ratio of 115.4 at the point of grid connection.

The wind farm was initially operated at unity power factor during normal operation, and hence the reactive power at the wind farm remained zero. Wind speed profiles were fed through the aggregated wind farm model (see Figure 1) to tune the controllers such that the simulation model power output agreed with the measured power output for the entire operating range of the DFIG ( $0.1 \mathrm{pu}$ to $1 \mathrm{pu}$ active power output). A comparison between the measured and simulated active power variations for the aggregated wind farm model during a 30 minute period is illustrated in Figure 3. 
The wind speed profile indicates a turbulence intensity of 0.08 while the active power output varies between 2.58-7.63 MW, and 99\% accuracy is achieved against the measured wind farm power output. In addition, the control performance of the aggregated wind farm model was further verified using wind profiles ranging from $4 \mathrm{~ms}^{-1}$ to $15 \mathrm{~ms}^{-1}$ (not shown).

\section{DFIG Reactive Power Capability}

The reactive power capability of a DFIG can be attributed to both the RSC and the GSC. Since this study is based around a 1.5 MW DFIG, reactive power capability charts were derived considering the limiting factors following the methodology outlined in [17-18]. The DFIG-RSC and GSC capability charts were derived separately in order to maximise the reactive power capability of the complete DFIG system.

\subsection{DFIG-RSC Reactive Power Capability}

The RSC reactive power capability is mainly constrained by the WRIG stator current, rotor current and rotor voltage limits [17-18]. These limiting factors further depend on the operating slip of the machine, and hence individual capability curves were produced for each slip value. The reactive power capability values for the intermediate slip values are calculated by a linear approximation function in DIgSILENT. Figure 4 illustrates the capability chart derived for the 1.5 MW DFIG-RSC using the generator parameters given in the Appendix.

The DFIG-RSC can operate between \pm 0.95 power factor across the operating range of the DFIG without additional reactive power support from the GSC. However, +0.90 power factor operation is limited to $0.90 \mathrm{pu}$ active power output and hence additional reactive power must be provided by the GSC beyond such conditions. In addition, the reactive power capability reduces with an increase in DFIG active power output.

\subsection{DFIG-GSC Reactive Power Capability}

The GSC reactive power capability is mainly limited by the DC link and the back-to-back converter ratings. The GSC capability chart was also derived in order to dispatch reactive power independently while coordinating with the RSC. The total active power output $\left(P_{t o t}\right)$ of the DFIG is comprised of both the stator $\left(P_{s}\right)$ and rotor power $\left(P_{r}\right)$ which can be denoted as follows:

$$
\begin{aligned}
& P_{t o t}=P_{s}+P_{r} \\
& P_{r}=-s P_{s}
\end{aligned}
$$

where, $s$ is the generator slip. From (1) and (2):

$$
P_{t o t}=\left(-P_{r} / s\right)+P_{r}=-\frac{P_{r}}{s}(1-s)
$$

If the converter and DC link losses are neglected: 
$P_{g c} \approx P_{r}$

The GSC reactive power capability $\left(Q_{g c}\right)$ depends on the active power transfer through the GSC $\left(P_{g c}\right)$ and the operating slip of the machine. Hence, if the GSC is rated at $S_{g c}$, the GSC reactive power capability can be derived from (3) and (4) as follows:

$Q_{g c} \approx \pm \sqrt{S_{g c}^{2}-P_{g c}^{2}}= \pm \sqrt{S_{g c}^{2}-P_{r}^{2}}$

$Q_{g c} \approx \pm \sqrt{S_{g c}^{2}-\left[-\frac{s P_{t o t}}{(1-s)}\right]^{2}}$

The 1.5 MW DFIG GSC capability chart for a $30 \%$ and $50 \%$ converter rating is illustrated in Figure 5.

The GSC capability chart indicates \pm 0.28 pu average reactive power capability for a $30 \%$ converter rating across its operating range, while for a $50 \%$ converter rating the average reactive power capability increases to $\pm 0.48 \mathrm{pu}$. Therefore, a $50 \%$ converter rating indicates a combined reactive power capability of $1.28 \mathrm{pu}$ during zero active power production, while during full active power production the reactive power reduces to $0.83 \mathrm{pu}$. Consequently, the DFIG possesses significant reactive power capability to support network requirements.

\subsection{RSC and GSC Coordinated Reactive Power Controller}

A coordinated reactive power controller was designed considering the RSC as the main controller with the GSC acting as the auxiliary controller (50\% converter rating). The coordinated control scheme between the GSC and RSC is shown in Figure 6. The RSC reactive power capability $(Q c c)$ is determined based on the capability curve of Figure 4 while considering the total active power output $\left(P_{m}\right)$ and operating slip $(s)$ of the DFIG. Then, $Q_{c c}$ is compared against the reactive power reference $\left(Q_{r e f}\right)$ of the DFIG system. The excess reactive power requirement becomes the reactive power reference for the GSC $\left(Q_{\text {gref }}\right)$. Therefore, the GSC is operated at unity power factor (see Figure 6) unless the reactive power requirement exceeds the RSC reactive capability. The reactive power reference is determined based on the control strategy of the DFIG. In the presented study $Q_{\text {ref }}$ is determined based on the multi-objective control schemes presented in Section 4. The reactive power reference $\left(Q_{r e f}\right)$ is used as the reactive power reference for the RSC $\left(Q_{r r e f}\right)$, since the RSC displays higher reactive power capability over the GSC, and is selected as the main reactive power controller for the proposed control scheme. Furthermore, the RSC reactive power capability is highly dependent on the operating slip of the machine, hence it can provide much enhanced reactive power performance during variable speed operation (i.e. variable slip) compared to the GSC.

An additional control droop was designed for the GSC when both controllers are dispatching reactive power at the PCC. In addition, both the RSC and GSC are designed with fast and slow controllers for phasor compensation and to generate the current reference [19]. Ultimately, the $d$-axis modulation factors for both the RSC $\left(m_{r d}\right)$ and the GSC $\left(m_{g d}\right)$ are determined by the respective controller. 
The control performance of the coordinated reactive power controller was analysed (see Figure 7) for two extreme VAr requirements (i.e. $+0.8 \mathrm{pu}$ and $-1.2 \mathrm{pu}$ ) using the wind profile of Figure 3-(a) (from $0 \mathrm{~s}$ to $600 \mathrm{~s}$ ). According to Figure 6 the DFIG RSC dispatches reactive power based on its capability curve in Figure 4 (for both operating conditions) while the excess reactive requirement is provided by the GSC. The dynamic performance of the coordinated VAr controller can be best understood by considering the time period 180-250 s, denoted as A in Figure 7.

During the time period between 180-250 s the wind speed increases which results in an increase in active power output $(\approx 1 \mathrm{MW})$ and subsequently the DFIG speed increases $(0.01 \mathrm{pu})$. Hence, the operating point on the DFIG-RSC capability chart moves upwards (see Figure 4). As illustrated in Figure 7-(c)/ (e) this results in a reduction in the reactive power capability of the DFIG $(0.02 \mathrm{pu}$ average reduction for both cases). Subsequently, the excess reactive power demand (0.6-0.7 pu) is diverted to the GSC (see $\mathbf{A}$ in Figure 7-(d)/ (f)) to deliver the total reactive power requirement.

\section{Multi-objective Reactive Power Control}

Reactive power can be controlled in multiple time frames based on the control objectives mandated by the utility operator. In multi-objective control the reactive power reference $\left(Q_{r e f}\right)$ is generated by decomposing the individual reactive requirements of the various control objectives.

\subsection{Control Strategies and Time Frames}

The reactive reference is updated based on the control objective stipulated by the wind or utility operator. Table 1 summarises the different control strategies and their reactive power reference update time frame.

As shown in Table 1, the reactive power reference is updated in different time frames and hence to deliver multiple control objectives it is essential to derive the individual requirements separately. Typically, voltage and power factor settings are fixed for a given location by the utility operator, however the reactive power reference may be updated in the seconds to minutes time frame during variable wind conditions. The aggregated reactive power requirement is fed through the novel coordinated reactive power controller. It is impractical to implement all objectives in the same time frame and location since individual objectives may conflict with each other (e.g. voltage and power factor control). Hence, only certain objectives can be implemented in multi-objective schemes with a weighting placed on each objective which can be represented as follows:

$$
Q_{\text {ref }}=W_{1} F_{1}(x)+W_{2} F_{2}(x) \leq Q\left(s, P_{m}\right)
$$

$F(x)$ and $W$ represent the objective function and the weighting placed on each respective objective function. The weightings can be adjusted to alter the contribution to the reactive power reference $\left(Q_{r e f}\right)$. Ultimately, the reactive power reference must satisfy the combined reactive power capability of the DFIG as implemented in the coordinated controller shown in Figure 6. 


\subsection{Multi-Objective Reactive Power Control}

This section evaluates various multi-objective reactive power control strategies under different system conditions. The reactive power reference $\left(Q_{r e f}\right)$ was derived for each multi-objective strategy considering the reactive power requirement for the main control scheme (i.e. power factor control, voltage control and reactive power dispatch) and the flicker mitigation scheme. The flicker control strategy is required since the main control scheme doesn't mitigate flicker emission due to the variable active power output of the wind generator during variable wind conditions.

\subsubsection{Power factor and flicker control}

One objective of a multi-objective strategy is to mitigate flicker emission from the wind turbine while maintaining the operating power factor within grid code standards. The reactive power reference was generated while considering both power factor control and flicker mitigation. According to [12], flicker emission due to active power fluctuations can be mitigated according to the following relation:

$$
\Delta Q=K_{R X} \Delta P ; \quad K_{R X} \approx-\left(\frac{R}{X}\right)
$$

The reactive power compensation gain $\left(K_{R X}\right)$ is based on the transmission line $\mathrm{X} / \mathrm{R}$ ratio which connects the wind farm substation and the grid. The average active power deviation $(\Delta P)$ is calculated with reference to the moving average of the power generated from the DFIG, which has also been used to generate the reactive power reference for power factor correction. Therefore, the reactive power reference can be derived using (7) including power factor correction as follows:

$$
Q_{r e f}=\underbrace{K_{R X}\left[\frac{1}{T_{a v}} \int_{0}^{T_{a v}}\left(P_{a v g}-P_{m}\right) d t\right]}_{Q_{f_{-} \text {ref }}}+\underbrace{P_{a v g}\left[\tan \left(\cos ^{-1}(p f)\right)\right]}_{Q_{p f_{-} r e f}}
$$

where, $P_{\text {avg }}, Q_{f_{-} \text {ref, }}, Q_{p f_{-} r e f}, T_{a v}$, and $p f$ denote the moving average of active power production, the reactive power reference for flicker mitigation, the reactive power reference for power factor control, the integration time constant for flicker reduction (set to $60 \mathrm{~s}$ ) and the power factor reference respectively. Both control strategies operate in the same time frame (i.e. one minute update frame) and hence the reactive power reference is updated once per minute. Figure 8 illustrates the multi-objective scheme for the power factor and flicker control strategies. The control performance of the multi-objective scheme was analysed using the wind speed profile in Figure 3-(a) and the test system in Figure 2.

Voltage and power factor performance for three operating strategies (i.e. multi-objective, power factor $(+0.98)$ and flicker control) are presented in Figure 9. The multi-objective strategy indicates a $0.01 \mathrm{pu}$ variation in the voltage profile compared to the flicker control strategy, while the power factor varies by 0.013\% compared to the power factor control strategy. Therefore, the multi-objective strategy indicates an improvement in system performance while adhering to the reactive power capabilities of the DFIG (average reactive power: $0.06 \mathrm{pu}$ ). In addition, an index was defined (multi-objective-performance index $(M O P I))$ to analyse the performance of the multi-objective strategies as follows: 
$M O P I=\left(1-\frac{|T P-A P|}{T P}\right)$

where, target performance $(T P)$ is the expected objective (e.g. power factor and voltage setting) from the controller while the actual performance $(A P)$ indicates the average actual performance. A higher $M O P I$ figure indicates that the actual performance is closer to the expected performance. A performance comparison for five operating conditions in multi-objective control is presented in Table 2.

According to Table 2, the operating power factor mainly deviated from expected performance when operating at capacitive power factors (e.g. +0.95 and +0.90$)$ due to the reactive power injective nature of the flicker mitigation strategy. However, the voltage deviation is insignificantly small for all the scenarios. When the DFIG is operating at low power factors, such as +0.90 , its reactive power requirement remains at $0.21 \mathrm{pu}$ for the multi-objective strategy, which is only $20 \%$ of the total reactive power capability (1.1 pu) of the DFIG (based on Figure 4 and Figure 5). Therefore, the average reactive power requirement is considerably below the total available capability from the DFIG for the power factor and flicker control strategy.

\subsubsection{Voltage and flicker Control}

The voltage control scheme maintains the PCC voltage at a predefined value set by the DNO, which then determines the associated reactive power requirement. However, it is essential to incorporate additional control schemes to control the voltage during large wind variations (i.e. during high wind turbulence). A multi-objective scheme designed for both voltage control and flicker mitigation is illustrated in Figure 10.

$$
Q_{v_{-} r e f}=K_{v r e f}\left(V_{m}-V_{r e f}\right)+\int_{t_{n}}^{t_{n+1}}\left(V_{m}-V_{r e f}\right) d t ; T_{v r e f}=t_{n+1}-t_{n}
$$

where $V_{m}, V_{\text {ref }}, K_{\text {vref, }}$, and $T_{\text {vref }}$ denote the voltage measurement at the PCC, voltage reference, voltage control gain and the voltage error integration time constant, respectively. The reactive power reference for the voltage control $\left(Q_{v_{-} \text {ref }}\right)$ scheme is updated every $100 \mathrm{~ms}$ while the reactive power reference for flicker was maintained at $1 \mathrm{~s}$. The control performance of the multi-objective scheme was analysed using the wind speed profile in Figure 3-(a) and the test system in Figure 2. The voltage performance for three operating strategies (i.e. multi-objective, voltage control and flicker control) is presented in Figure 11.

The voltage set point for both the voltage and multi-objective control strategies was chosen as $1.017 \mathrm{pu}$ in order to make a fair comparison with the flicker control strategy. It can be seen that the multi-objective strategy provides improved voltage control performance in comparison to the flicker and voltage control strategies. The reactive power requirement for all three strategies varies between -0.06 to $+0.11 \mathrm{pu}$, which is within the reactive power capability of the DFIG.

\subsubsection{System VAr Support with Flicker Control}

The DFIG reactive power capability can also be utilised to deliver system reactive power requirements to minimise system losses or the generation fuel cost [9-10]. Therefore, a multi-objective scheme can be developed to deliver TSO/DSO VAr requirements while reducing voltage fluctuations during variable 
wind conditions. A control scheme which aggregates the system and flicker mitigation reactive power requirements was designed (similar to Figure 8 and Figure 10) for a multi-objective strategy. A comparison between the multi-objective and system VAr dispatch strategies for two different reactive power requirements using the wind speed variation in Figure 3-(a) is shown in Figure 12.

It can be seen that when dispatching reactive power during variable wind conditions (assuming that the reactive power setting is updated every 15 minute period) the voltage deviates between $0.76-3.41 \%$ for the system VAr dispatch strategy compared to the voltage profile of the multi-objective strategy. Despite, the decreased voltage variation, the wind farm reactive power dispatch varies significantly (e.g. $+0.5 \mathrm{pu}$ : 0.49 to 0.63 pu and $-0.5 \mathrm{pu}$ : -0.38 to $-0.51 \mathrm{pu}$ ) which may affect the system loss reduction.

\section{Dynamic Performance Analysis}

The dynamic performance of the multi-objective strategies were evaluated with different wind profiles and network conditions using the test network in Figure 2. The short-term flicker severity $\left(P_{\mathrm{st}}\right)$ and $M O P I$ were used as the main indices to analyse the performance of the multi-objective strategies while the shortterm flicker severity was measured in accordance with IEC 61000-4-15 [20]. The multi-objective power factor control strategy was operated with a 0.9 leading power factor target, the voltage control setting was $1.05 \mathrm{pu}$ and the system VAr dispatch target was $0.8 \mathrm{pu}$.

\subsection{Performance with Different Wind Profiles}

Mean wind speed and turbulence intensity are the two main characteristics of a wind profile which directly influence flicker emission [13] and hence affect the reactive power requirement. This analysis has been carried out assuming an X/R ratio of 1 for the transmission line and a SCR of 115.4 at the grid connection point. The different mean wind speed values used for the dynamic simulations indicate various operating points (i.e. cut-in, power-optimisation and cut-off regions) of the maximum power tracking (MPT) curve of the DFIG [16]. The short-term flicker severity, reactive power performance and $M O P I$ for a range of mean wind speeds and turbulence intensities for the three multi-objective strategies are shown in Figure 13.

It can be seen that comparatively high $P_{\text {st }}$ values are reported (see Figure 13) when the wind speed varies between $10-12.5 \mathrm{~ms}^{-1}$, since the wind turbine control strategy changes from a power optimisation to a power limitation strategy [19], which leads to much greater active power fluctuations when operating within this wind speed range. This has further affected the performance (see Figure 13-(a)) of the multiobjective strategies; in particular, power factor and system VAr dispatch, since much higher reactive power is required to mitigate the flickering effect.

High short-term flicker severity can be seen for the power factor control strategy compared to the voltage and system VAr dispatch strategies. As an example, at a wind speed of $14 \mathrm{~ms}^{-1}$ the flicker severity $\left(P_{\mathrm{st}}\right)$ is 0.1 for the power factor control strategy while for the voltage and system VAr dispatch strategies it is only 0.025 and 0.02 respectively. This is because the multi-objective voltage control strategy applies two control schemes to rectify voltage fluctuations while the system VAr dispatch strategy effectively negates 
the voltage fluctuations due to active power fluctuations by dispatching more reactive power $(0.8 \mathrm{pu}$ reactive power injection) to the network. In addition, the reactive power requirement for the voltage control strategy has been progressively decreased (see Figure 13-(a)), since higher wind speeds imply higher active power output, but the reactive power capability to maintain the voltage at a higher value (i.e. $1.05 \mathrm{pu})$ is decreased.

High wind turbulence intensity has resulted in large $P_{\text {st }}$ values due to the high active power fluctuations of the wind farm. This can be observed for all three multi-objective strategies. As an example, for the multiobjective power factor control strategy there is a short-term flicker severity of 0.014 for 0.01 wind turbulence intensity which then increases to 0.15 at 0.1 wind turbulence intensity. In addition, the system VAr dispatch strategy has shown improved flicker mitigation performance for high turbulence intensities (e.g. a $P_{\text {st }}$ of 0.099 for the voltage control strategy and 0.026 for the system VAr dispatch strategy at a wind turbulence intensity of 0.1 ), since high reactive power output from the VAr dispatch strategy effectively reduces the voltage sensitivity due to active power variations. However, the MOPI index is low compared to the other multi-objective strategies. In contrast, the multi-objective voltage control is able to keep the average system voltage at $1.05 \mathrm{pu}$ despite instantaneous variations, and maintains maximum MOPI performance under both varying wind speed and turbulence intensities.

\subsection{Performance with Different Network Characteristics}

The network conditions also affect the performance of the multi-objective strategies, in particular the $\mathrm{X} / \mathrm{R}$ ratio (grid impedance angle $\left(\psi_{k}=\tan ^{-1}(\mathrm{X} / \mathrm{R})\right.$ of the transmission line and the short-circuit ratio of the grid connection point. The wind profile shown in Figure 3-(a) was used for the study and the $\mathrm{X} / \mathrm{R}$ ratio (grid impedance angle) was varied while maintaining the line impedance constant. X/R ratios corresponding to grid impedance angles of $30^{\circ}, 50^{\circ}, 70^{\circ}$, and $85^{\circ}$ were specifically chosen to comply with the flicker measurement standards [20-21]. The dynamic performance of the multi-objective strategies under different network conditions is shown in Figure 14.

The short-term flicker severity has decreased with an increase in SCR (see Figure 14-(a)) since the grid voltage becomes stiffer. The reactive power requirement for both the power factor control and system VAr dispatch strategies remains constant while that for the voltage control strategy indicates a steady increase with an increase in SCR. As an example, for a SCR of 10 the reactive power is $0.44 \mathrm{pu}$, but this increases to $0.74 \mathrm{pu}$ when the SCR increases to 200. This is because when the SCR increased the grid voltage exceeds $1.05 \mathrm{pu}$, and hence additional reactive power must be absorbed to maintain the voltage at the specified value.

An increase in $X / R$ ratio has significantly reduced the flicker emission for all three strategies as a consequence of the reduction in active power dependency of the voltage due to low line resistance. As an example, for the system VAr dispatch strategy the short-term flicker severity is 0.022 for an $\mathrm{X} / \mathrm{R}$ ratio of 0.58 , which then reduces to 0.014 when the $\mathrm{X} / \mathrm{R}$ ratio increases to 11.4 ( $85^{\circ}$ grid impedance angle). In addition, the reactive power requirement has also been significantly reduced with an increase in the $\mathrm{X} / \mathrm{R}$ ratio, since the voltage fluctuations were reduced due to the weakened voltage dependency on active 
power. The MOPI has also improved, since the reactive power requirement for the flicker mitigation strategy has reduced with an increase in both the short-circuit and $\mathrm{X} / \mathrm{R}$ ratios.

\section{Discussion}

This study has demonstrated the feasibility of delivering multiple reactive power objectives without additional hardware improvements for the DFIG. Therefore, utility operators can request multi-objective reactive power control capabilities from wind farm operators, and those who enable such capabilities can be financially rewarded. As an example, in Spain an $8 \%$ bonus is given to wind farm operators who dispatch reactive power while operating at a requested power factor from 0.95 leading to 0.95 lagging during peak, normal and valley periods [22].

The in-built communication infrastructure for smart power networks can be utilised to enable multiobjective control capabilities from wind farms. Eventually, DSOs and TSOs can select wind farms in optimal locations to harness the reactive power capability to deliver multiple network requirements. The weighting for each control input of a multi-objective strategy can be determined based on the allowable range for the control objective (e.g. $\pm 6 \%$ voltage variation), and hence the control gains can be adjusted to change the balance between control objectives.

The short-term flicker severity $\left(P_{\mathrm{st}}\right)$ values for the multi-objective strategies lie within the stipulated standards for low and medium voltage distribution feeders [21]. Hence, the flicker mitigation strategy can be implemented together with the main reactive power control objective for power quality improvement. Furthermore, the reactive capability chart based approach can also be used to enhance the FRT performance while maximising the reactive power dispatch during grid disturbances. Thus, the transient operating mode can be activated with the detection of a voltage dip in the network, as demonstrated in [5]. Moreover, the multi-objective reactive power control concept should be equally applicable to FCWGs, since they provide full reactive power capability over their operating range.

\section{Conclusions}

The DFIG capability to deliver multiple reactive power objectives was examined in this study while considering an actual DFIG wind farm located at a remote location in the N. Ireland system. A novel coordinated reactive power controller was developed for the RSC and the GSC considering their individual reactive power characteristics and it has shown its capability to maximise the reactive power capability of the DFIG wind farm to deliver multiple network objectives. Three multi-objective schemes have been analysed under a wide range of operating conditions and it was shown that multiple reactive power objectives can be delivered without significantly compromising the main control objective (i.e. voltage, and power factor control, etc.). The study has been further extended to analyse the impact under different wind profiles and network characteristics, and it was demonstrated that network performance and power quality can be improved under extreme operating conditions while adhering to the existing reactive power capability of the DFIG. This study has also demonstrated that DFIGs can deliver multiple reactive power objectives without need for additional reactive power compensation devices installed in power networks. 


\section{Acknowledgement}

This work has been financially support by Endeavour Energy Power Quality and Reliability Centre (EEPQRC), NSW, Australia and Science Foundation Ireland (Grant no: 06/CP/E002).

\section{Appendix}

1.5 MW DFIG parameters: rated stator voltage: $0.69 \mathrm{kV}$; rated rotor voltage: $1863 \mathrm{~V}$; rated apparent power: 1,667 kVA; rated speed: $1800 \mathrm{rpm}$; no. pole pairs: 2; stator resistance: $0.01 \mathrm{pu}$; stator reactance: $0.1 \mathrm{pu}$; rotor reactance: $0.1 \mathrm{pu}$; rotor resistance: $0.01 \mathrm{pu}$; magnetising reactance: $3.5 \mathrm{pu}$; generator inertia: $75 \mathrm{kgm}^{2}$; turbine inertia: 4,052,442 $\mathrm{kgm}^{2}$; shaft stiffness: $83,000,000 \mathrm{Nm} / \mathrm{rad}$. 


\section{List of Symbols}

$\psi_{k} \quad$ Grid impedance angle

$\omega_{g} \quad$ Generator shaft speed

$F(x) \quad$ Objective function

$I_{r} \quad$ Rotor current

$K_{R X} \quad$ Reactive power compensation gain

$K_{\text {vref }} \quad$ Voltage control gain

$m_{r d}, m_{g d} \quad d$-axis modulation factors for the RSC and GSC

$P_{\text {avg }} \quad$ Moving average of active power production

Pf power factor reference

$P_{g c} \quad$ power transfer through the GSC

$P_{\text {gref }} \quad$ Active power reference of GSC

$P_{m} \quad$ Total active power output

$P_{\text {mea }} \quad$ Active power measurement at PCC

$P_{\text {mech }} \quad$ Mechanical power input to the generator

$P_{\text {ref }} \quad$ Active power reference of RSC

$P_{r} \quad$ Active power output from rotor

$P_{s} \quad$ Active power output from stator

$P_{\text {st }} \quad$ Short-term flicker severity

$P_{\text {tot }} \quad$ Total active power output

$Q_{c c} \quad$ RSC reactive power capability

$Q_{f_{-} \text {ref }} \quad$ Reactive power reference for flicker mitigation

$Q_{g c} \quad$ Reactive power capability of GSC

$Q_{\text {gref }} \quad$ Reactive power reference of GSC

$Q_{\text {mea }} \quad$ Reactive power measurement at PCC

$Q_{p f_{-} \text {ref }} \quad$ Reactive power reference for power factor control

$Q_{r} \quad$ Reactive power output of rotor

$Q_{\text {ref }} \quad$ Reactive power reference of RSC

$Q_{s} \quad$ Reactive power output of stator

$Q_{v_{-} \text {ref }} \quad$ Reactive power reference for the voltage control

$S_{g c} \quad$ GSC rating

$s \quad$ Slip

$T_{a v} \quad$ Integration time constant for flicker reduction

$T_{\text {vref }} \quad$ Voltage error integration time constant

$U_{W} \quad$ Wind speed

$V_{a c} \quad$ AC voltage at the point of common coupling (PCC)

$V_{d c} \quad$ DC link voltage

$V_{m} \quad$ Voltage measurement at the PCC

$V_{\text {ref }} \quad$ Voltage reference

$W \quad$ Weighting placed on objective function 


\section{References}

[1] Ackermann T. (2 ${ }^{\text {nd }}$ Ed). Wind Power in Power Systems. Wiley, 2005.

[2] Fox B, Flynn D, Bryans L, Jenkins N, Milborrow D, O' Malley M, Watson R. Wind Power Integration: Connection and System Operation Aspects. IET, 2007.

[3] Martinez E, Sanz F, Blanco J, Daroca F, Jimenez E. Economic analysis of reactive power compensation in a wind farm: influence of Spanish energy policy. Renewable Energy 2008; 33(8): $1880-1891$.

[4] Ullah NR, Bhattacharya $\mathrm{K}$, Thiringer $\mathrm{T}$. Wind farms as reactive power ancillary service providers - technical and economic issues. IEEE Transactions on Energy Conversion 2009; 24(3): 661-672.

[5] Meegahapola LG, Littler T, Flynn D. Decoupled-DFIG fault ride-through strategy for enhanced stability performance during grid faults. IEEE Transactions on Sustainable Energy 2010; 1(3): 52162.

[6] Kayikci M, Milanovic JV. Reactive power control strategies for DFIG-based plants. IEEE Transactions on Energy Conversion 2007; 22(2): 389-396.

[7] Ullah NR, Thiringer T. Variable speed wind turbines for power system stability enhancement. IEEE Transactions on Energy Conversion 2007; 22(1): 52-60.

[8] Ullah NR, Thiringer T, Karlsson, D. Voltage and transient stability support by wind farms complying with the E.ON Netz grid code. IEEE Transactions on Power Systems 2007; 22(4): 1647-1656.

[9] Meegahapola L, Durairaj S, Flynn D, Fox B. Coordinated utilisation of wind farm reactive power capability for system loss optimisation. European Transactions on Electrical Power 2011; 21(1): 40-51.

[10] Konopinski RJ, Vijayan P, Ajjarapu V. Extended reactive capability of DFIG wind parks for enhanced system performance. IEEE Transactions on Power Systems 2009; 24(3): 1346-1355.

[11] De Oliveira-De Jesus, PM, Castronuovo ED, Ponce de Leao, MT. Reactive power response of wind generators under an incremental network loss allocation approach. IEEE Transactions on Energy Conversion 2008; 23(2): 612-621.

[12] Meegahapola L, Flynn D, Fox, B. Flicker mitigation strategy for DFIGs during variable wind conditions. IEEE PES GM 2010, Minneapolis, USA, 2010.

[13] Sun T, Chen Z, Blaabjerg F. Flicker study on variable speed wind turbines with doubly fed induction generators. IEEE Transactions on Energy Conversion 2005; 20(4): 896- 905.

[14] National Grid Electricity Transmission PLC, The Grid Code, ver. 4, rev. 8, 2011.

[15] EirGrid plc, Grid Code, ver. 3.5, 2011. 
[16] Miller NW, Price WW, Sanches-Gasca, JJ. Dynamic modeling of GE 1.5 and 3.6 MW wind turbine generators, General Electric, ver. 3.0, 2003.

[17] Lund T, Sørensen P, Eek J. Reactive power capability of a wind turbine with doubly fed induction generator. Wind Energy 2007; 10: 379-394.

[18] Engelhardt S, Erlich I, Feltes C, Kretschmann J, Shewarega F. Reactive power capability of wind turbines based on doubly fed induction generators. IEEE Transactions on Energy Conversion 2011; 26(1): 364-372.

[19] Hansen, A.D., Jauch, C., Sørensen, P., Iov, F., and Blaabjerg, F., Dynamic wind turbine model in power system simulation tool DIgSILENT, Riso Report-1400, 2003.

[20] IEC 61000-4-15: Testing and measurement techniques-Flickermeter-Functional and design specifications. $\left(2^{\text {nd }}\right.$ Ed). 2010.

[21] IEC 61000-3-7: Assessment of emission limits for the connection of fluctuating installations to MV, $H V$ and EHV power systems. ( $\left.2^{\text {nd }} E d\right) .2008$.

[22] Martinez E, Sanz F, Blanco J, Daroca F, Jimenez E. Economic analysis of reactive power compensation in a wind farm: influence of Spanish energy policy. Renewable Energy 2008; 33(8): $1880-1891$. 


\section{Tables}

Table 1: Control Strategies for Reference Update Time Frames

\begin{tabular}{|c|c|}
\hline Time Frame & Control Objective \\
\hline minutes to hours & System VAr support, Loss minimisation \\
\hline seconds to minutes & Voltage control, Power factor control, Flicker mitigation \\
\hline milliseconds to seconds & FRT- transient voltage support \\
\hline
\end{tabular}

Table 2: Performance of the Multi-Objective Strategy

\begin{tabular}{|c|c|c|c|}
\hline \multirow{2}{*}{ Power Factor } & \multirow{2}{*}{$\begin{array}{c}\text { Max. Reactive Power } \\
\text { Dispatch (pu) }\end{array}$} & \multicolumn{2}{|c|}{ MOPI } \\
\hline & & PF & Voltage \\
\hline unity pf & 0.11 & 0.98 & 1.00 \\
\hline$+0.95 \mathrm{pf}$ & 0.18 & 0.93 & 1.00 \\
\hline$-0.95 \mathrm{pf}$ & 0.13 & 0.96 & 1.00 \\
\hline$+0.90 \mathrm{pf}$ & 0.21 & 0.92 & 1.00 \\
\hline$-0.90 \mathrm{pf}$ & 0.18 & 0.94 & 1.00 \\
\hline
\end{tabular}




\section{Figure Titles}

Figure 1: DFIG simulation model.

Figure 2: Test system.

Figure 3: DFIG model validation (a) Wind speed variation (b) Comparison of actual and simulated active power output of the wind farm.

Figure 4: DFIG-RSC reactive power capability chart.

Figure 5: GSC capability chart.

Figure 6: RSC and GSC coordinated reactive power controller.

Figure 7: Performance of the coordinated controller (a) Active power output (b) DFIG speed (c) Reactive power of the RSC (0.8 pu injection) (d) Reactive power of the GSC ( 0.8 pu injection) (e) Reactive power of the RSC (1.2 pu absorption) (f) Reactive power of the GSC (1.2 pu absorption).

Figure 8: Multi-objective scheme for power factor and flicker control

Figure 9: Performance comparison for different operating strategies (a) PCC voltage (b) power factor.

Figure 10: Multi-objective scheme for voltage and flicker control

Figure 11: Voltage variation at the PCC for different operating strategies.

Figure 12: Performance comparison for multi-objective startegy (a) 0.5 pu reactive power injection (b) 0.5 reactive power absorption.

Figure 13: Performance comparison for multi-objective strategies with different wind profiles (a) Mean wind speed (b) Wind turbulence intensities.

Figure 14: Performance comparison for multi-objective strategies with different network conditions (a) Short-circuit ratio (SCR) (b) X/R ratios 
Figures

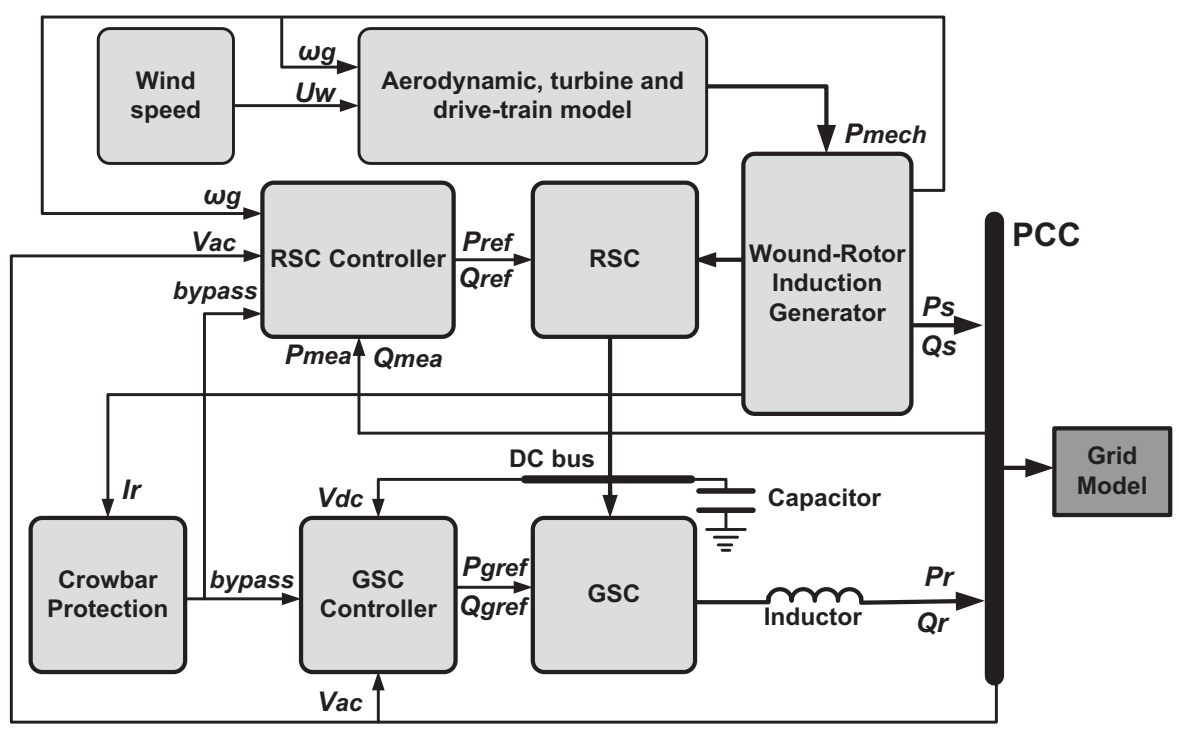

Figure 1: DFIG simulation model.

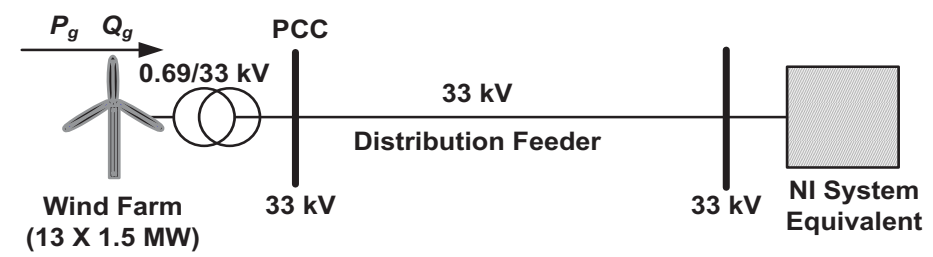

Figure 2: Test system.

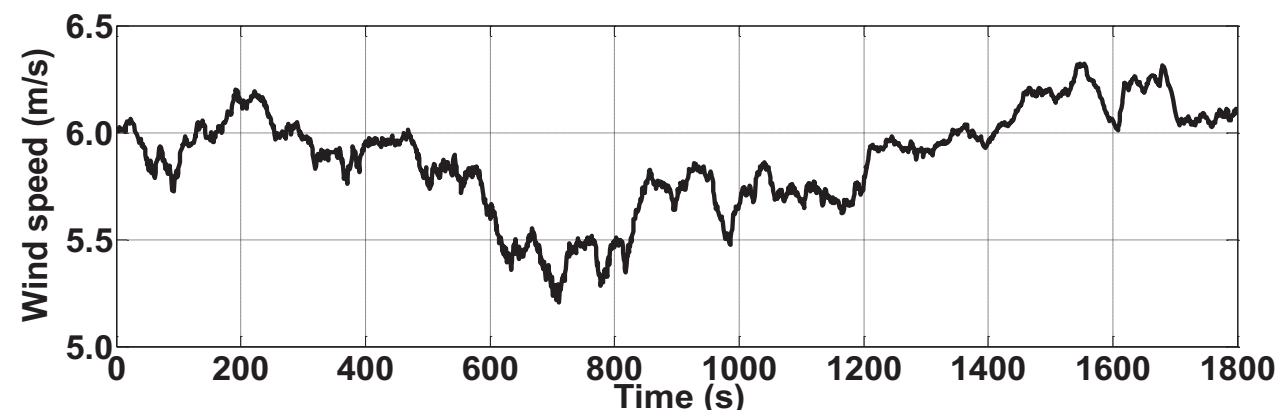

(a)

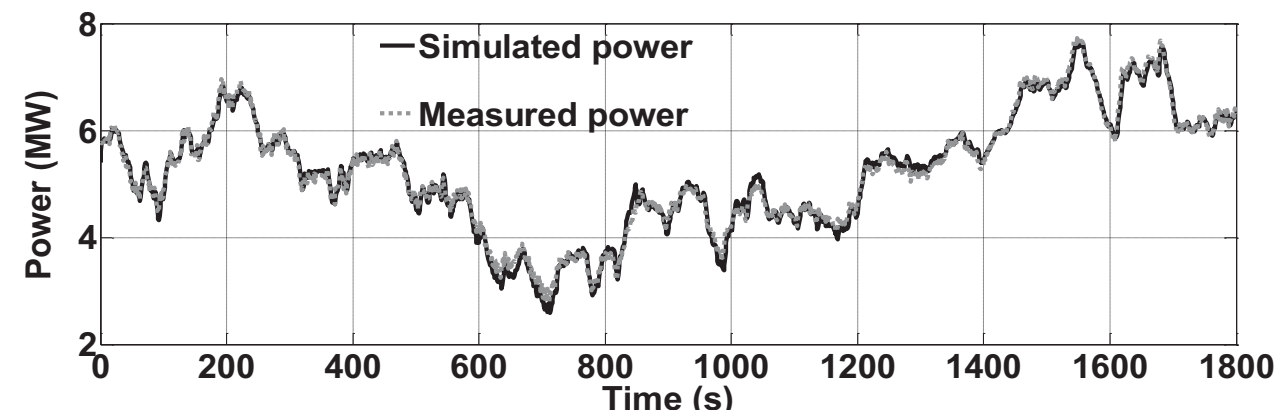

(b)

Figure 3: DFIG model validation (a) Wind speed variation (b) Comparison of actual and simulated active power output of the wind farm. 


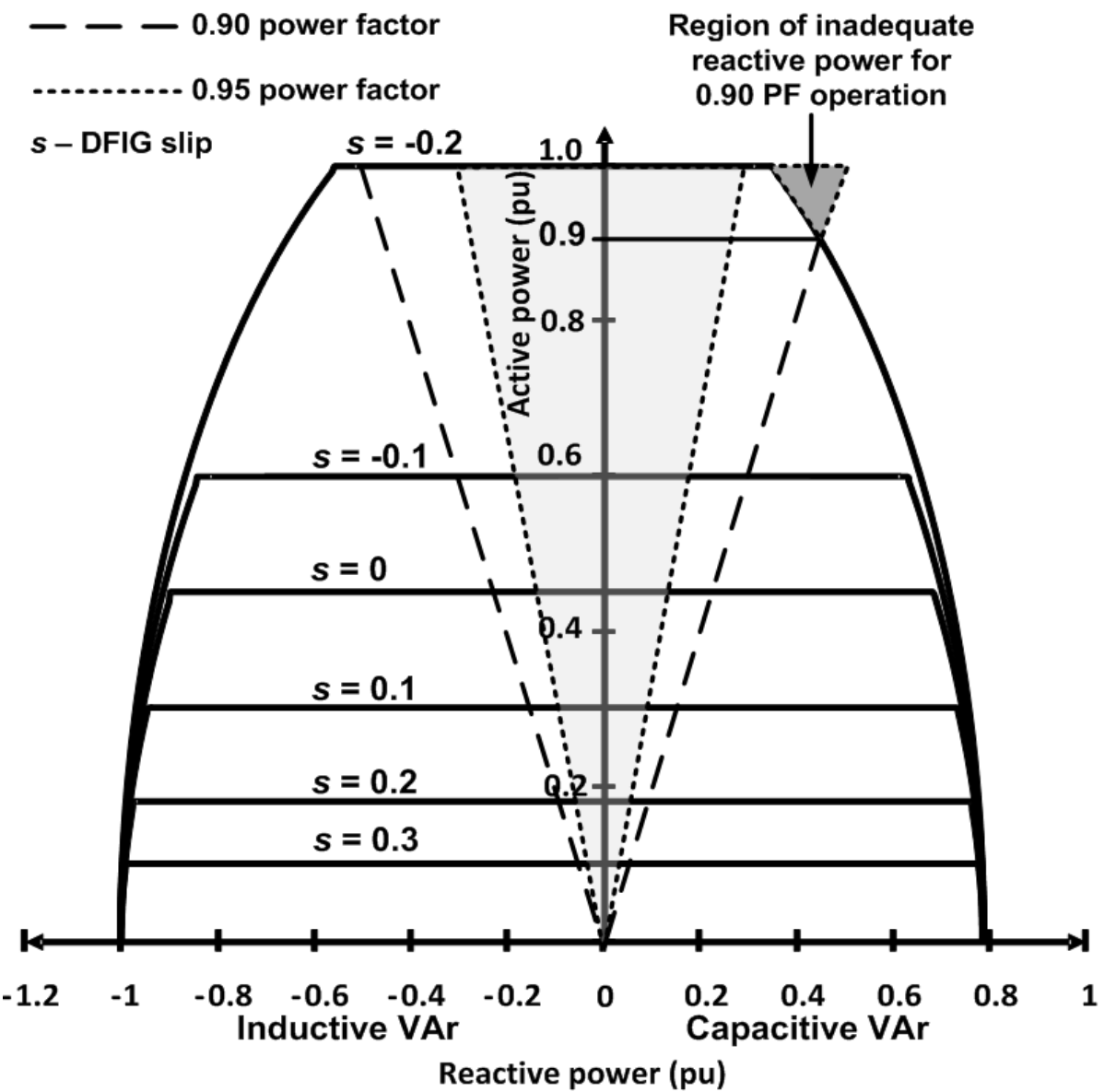

Figure 4: DFIG-RSC reactive power capability chart.

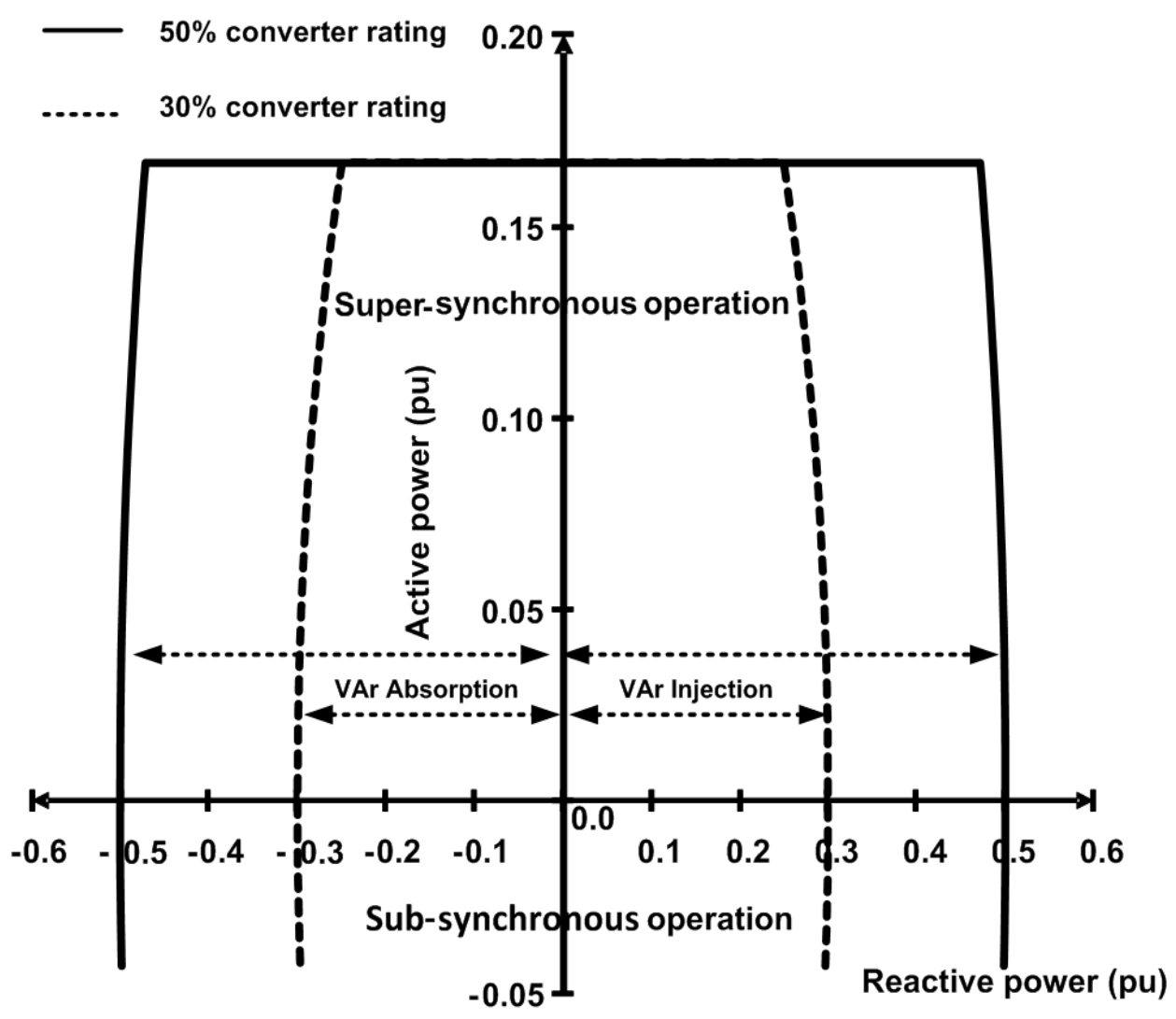

Figure 5: GSC capability chart. 


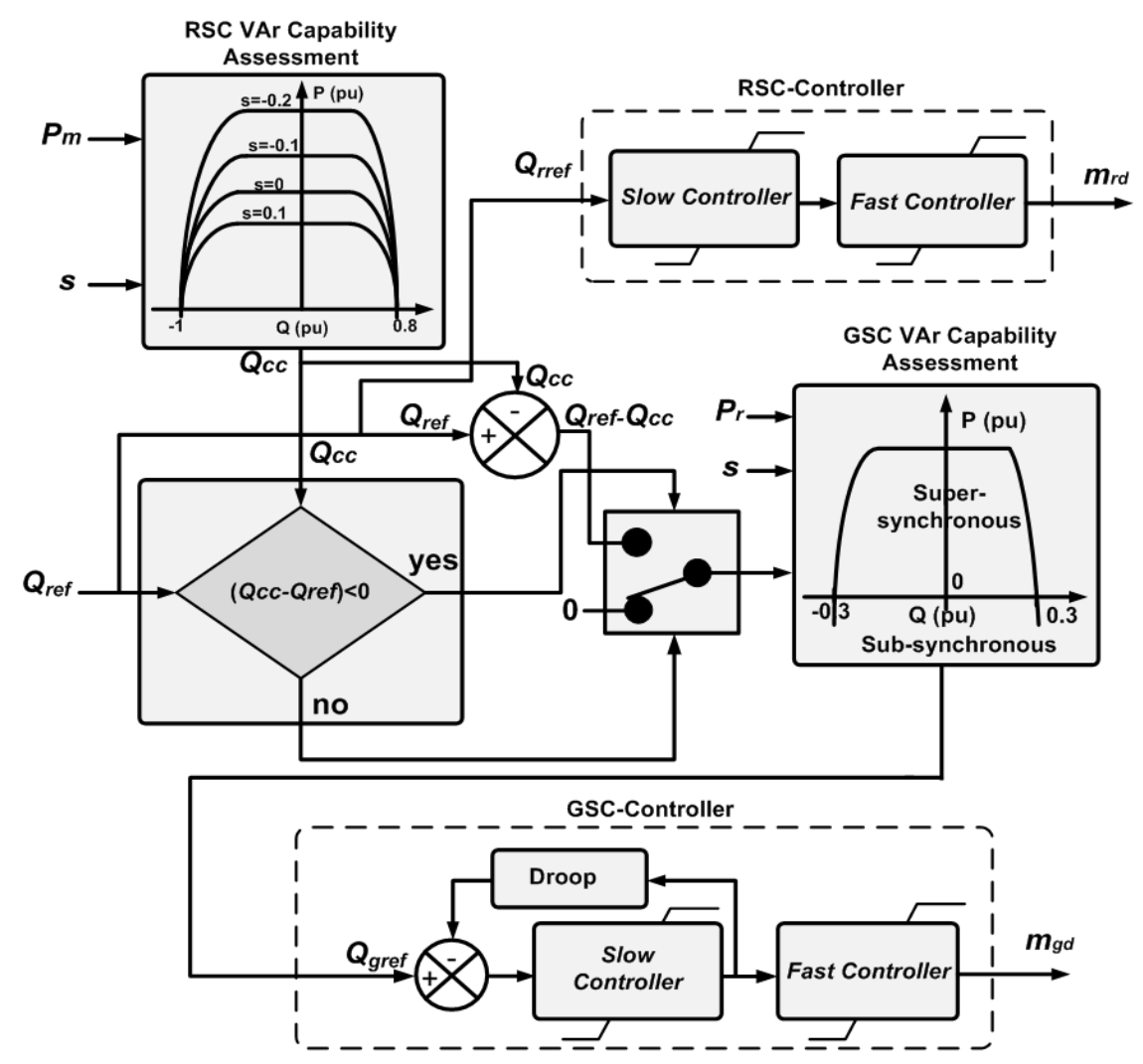

Figure 6: RSC and GSC coordinated reactive power controller.
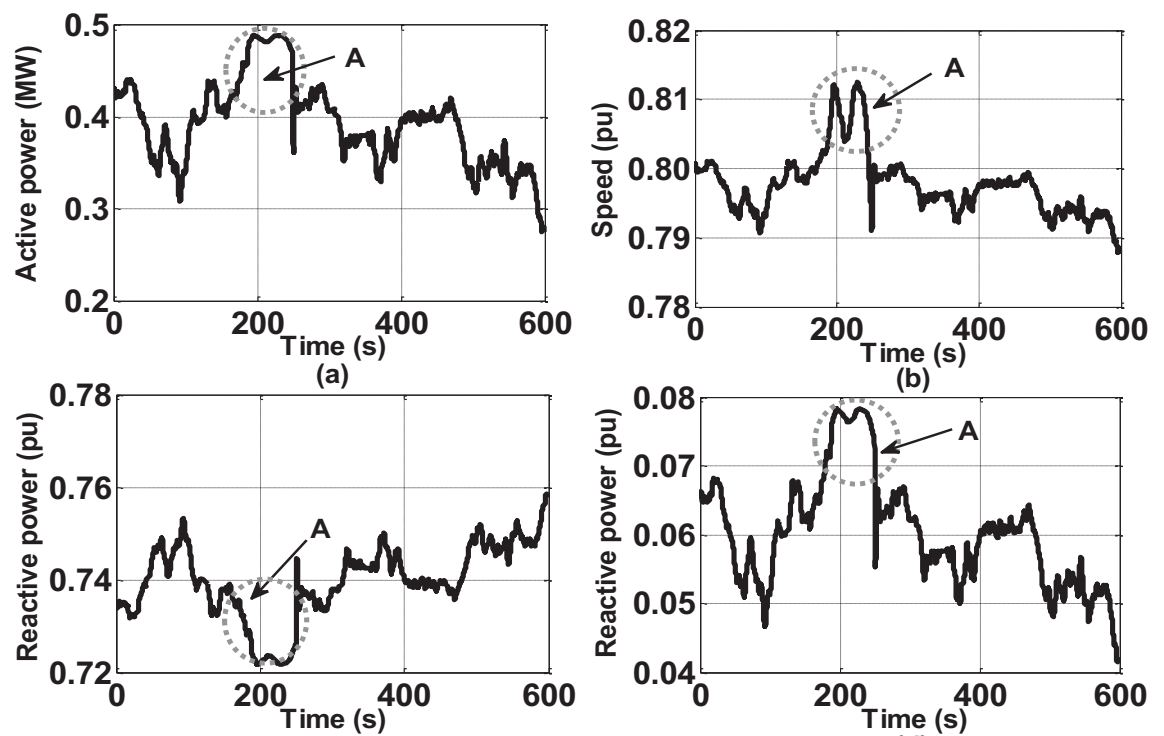

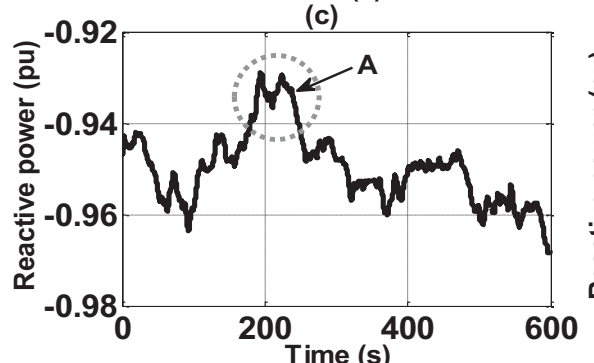

(e)

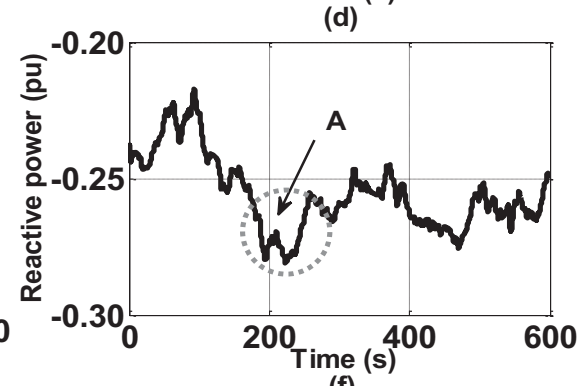

(f)

Figure 7: Performance of the coordinated controller (a) Active power output (b) DFIG speed (c) Reactive power of the RSC ( 0.8 pu injection) (d) Reactive power of the GSC (0.8 pu injection) (e) Reactive power of the RSC (1.2 pu absorption) (f) Reactive power of the GSC (1.2 pu absorption). 


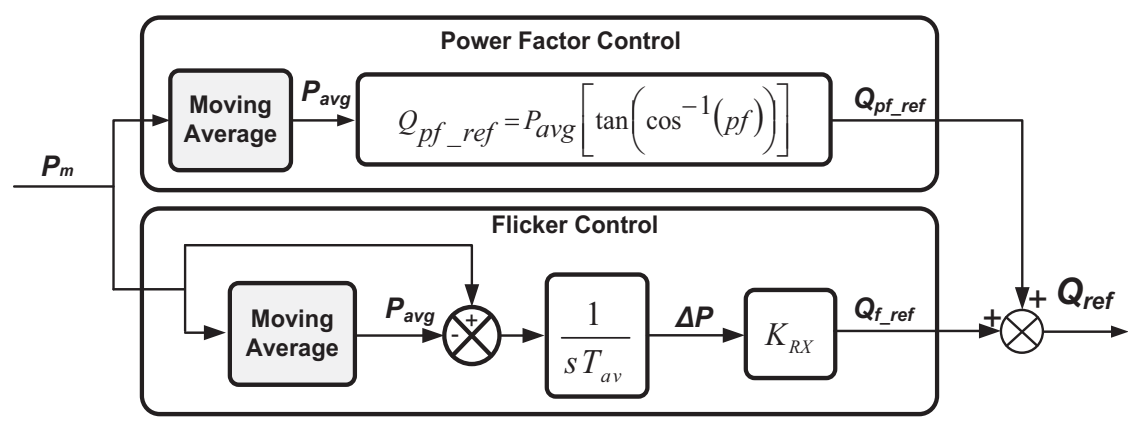

Figure 8: Multi-objective scheme for power factor and flicker control

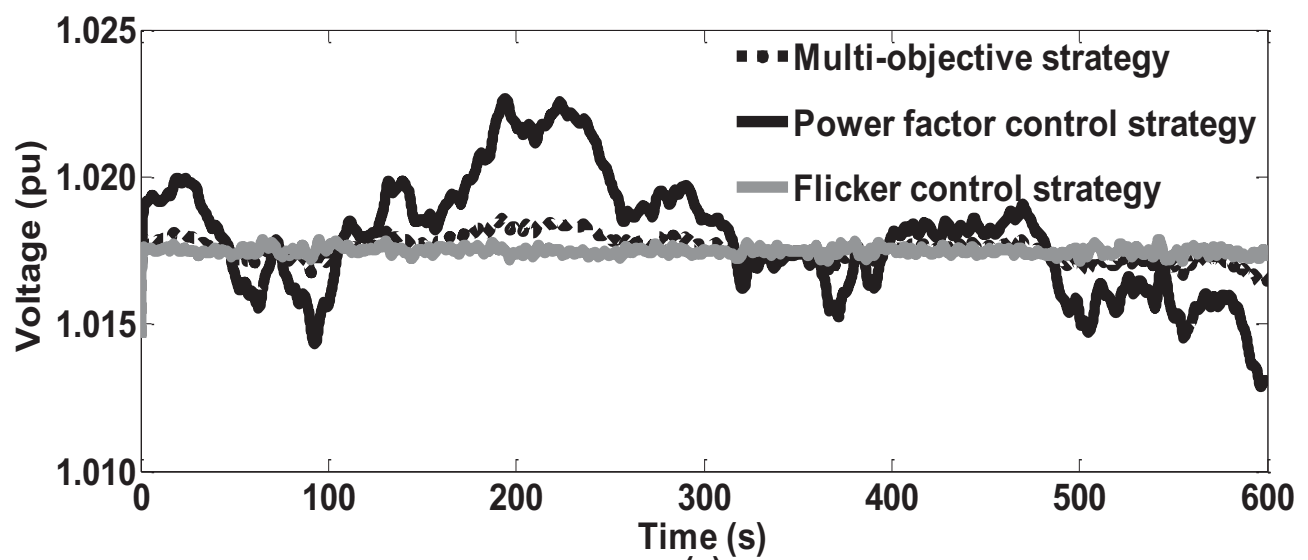

(a)

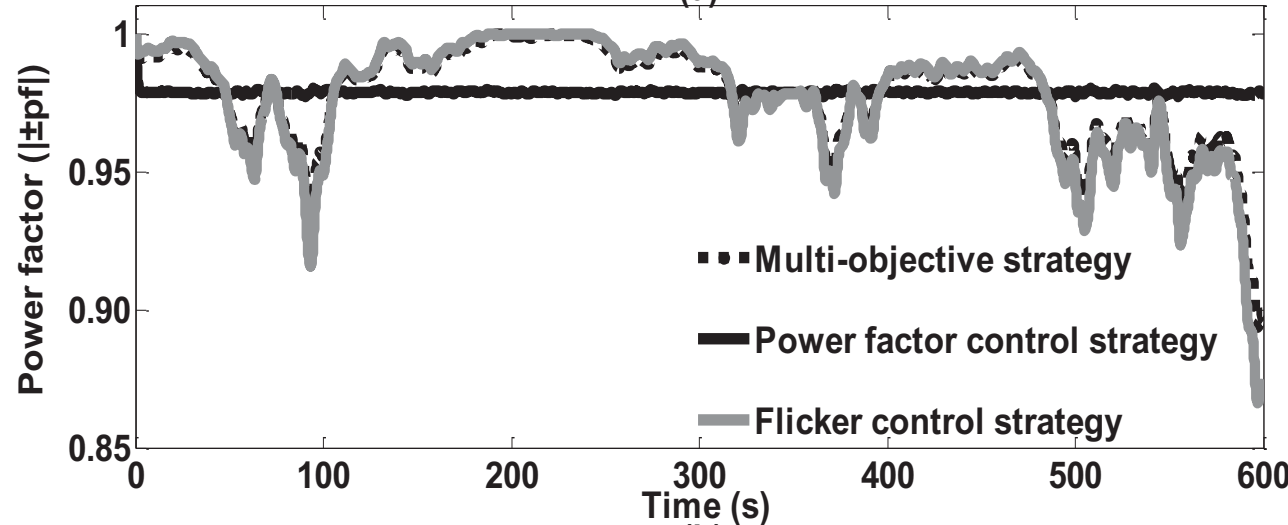

(b)

Figure 9: Performance comparison for different operating strategies (a) PCC voltage (b) power factor.

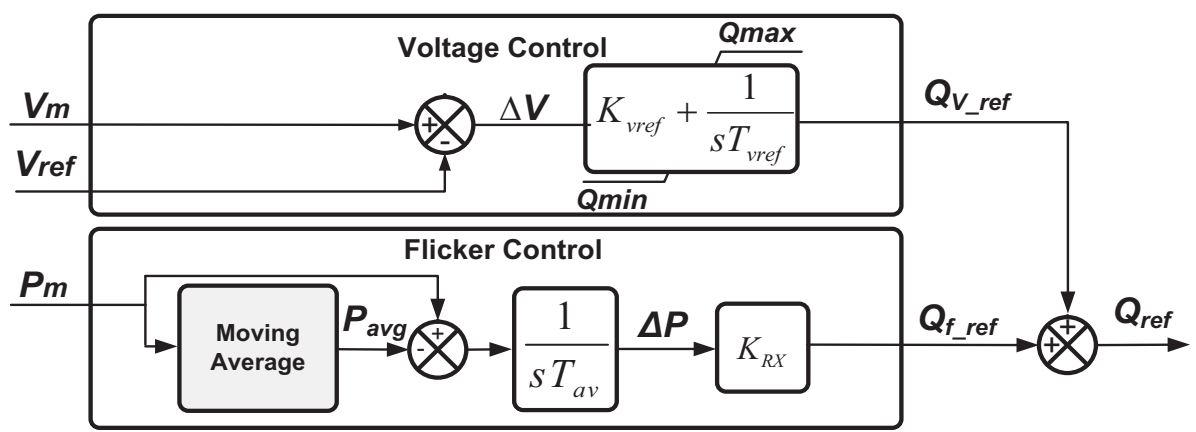

Figure 10: Multi-objective scheme for voltage and flicker control 


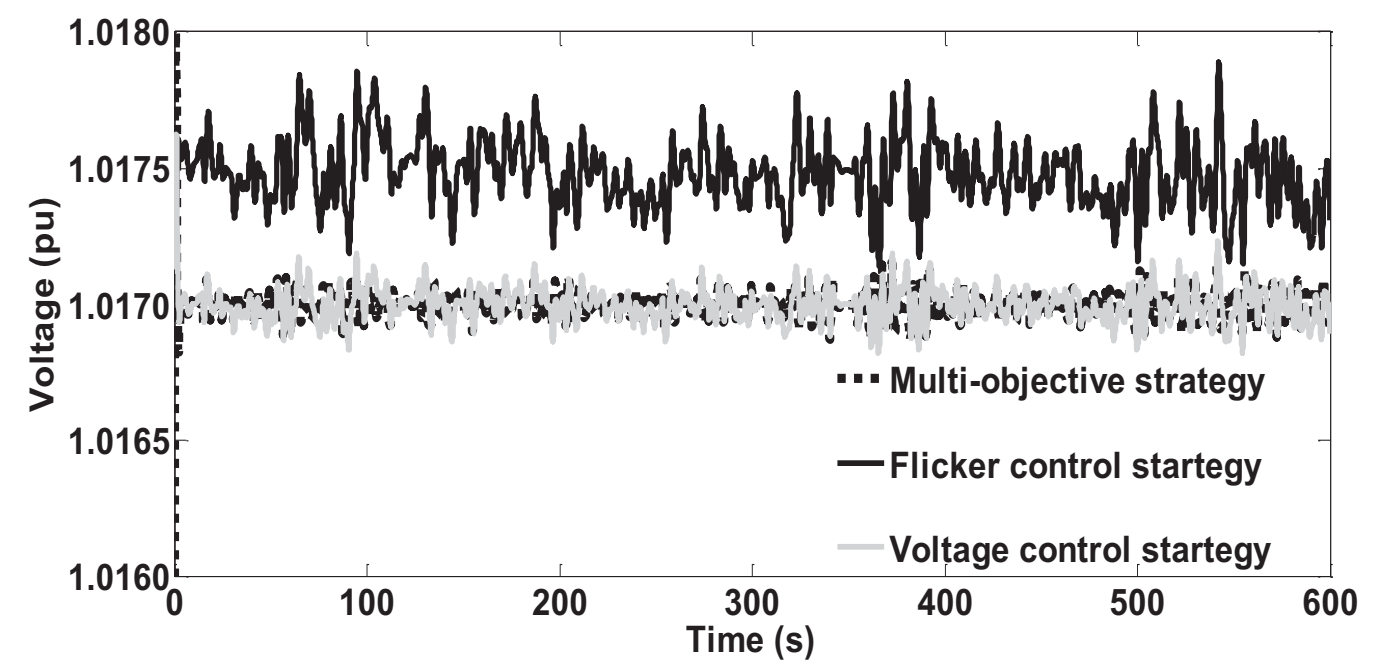

Figure 11: Voltage variation at the PCC for different operating strategies.
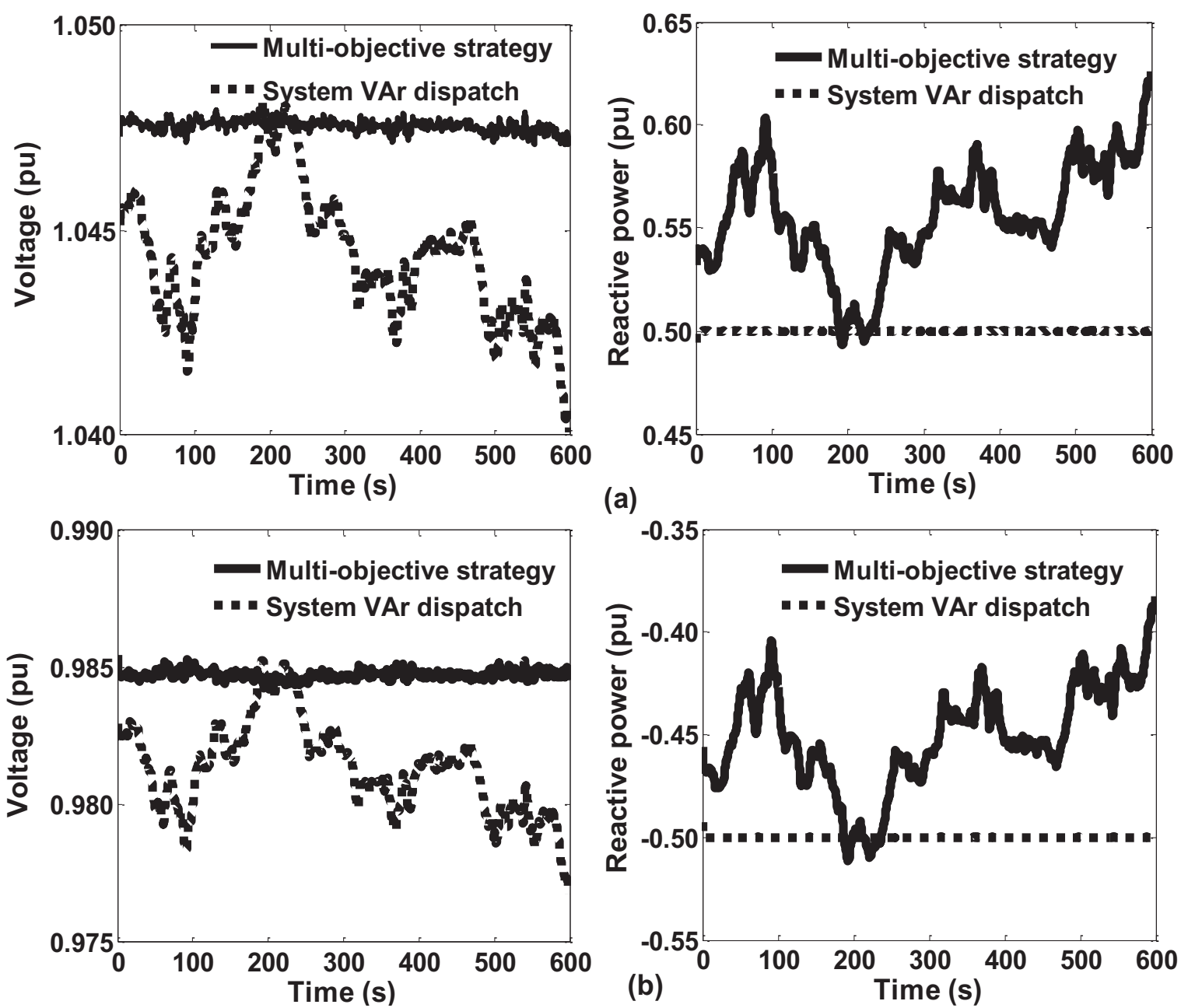

Figure 12: Performance comparison for multi-objective startegy (a) 0.5 pu reactive power injection (b) 0.5 reactive power absorption. 

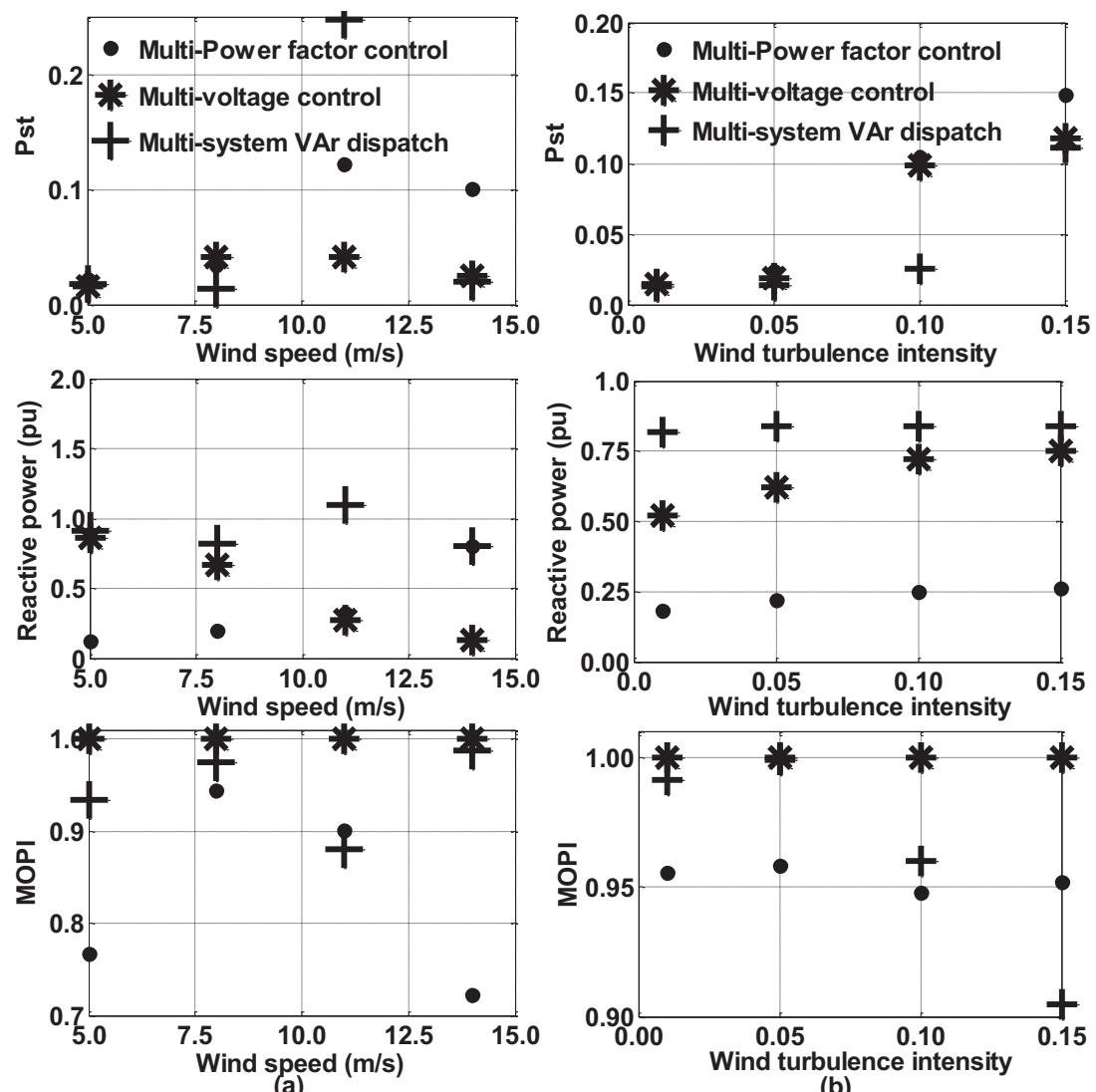

(b)

Figure 13: Performance comparison for multi-objective strategies with different wind profiles (a) Mean wind speed (b) Wind turbulence intensities.
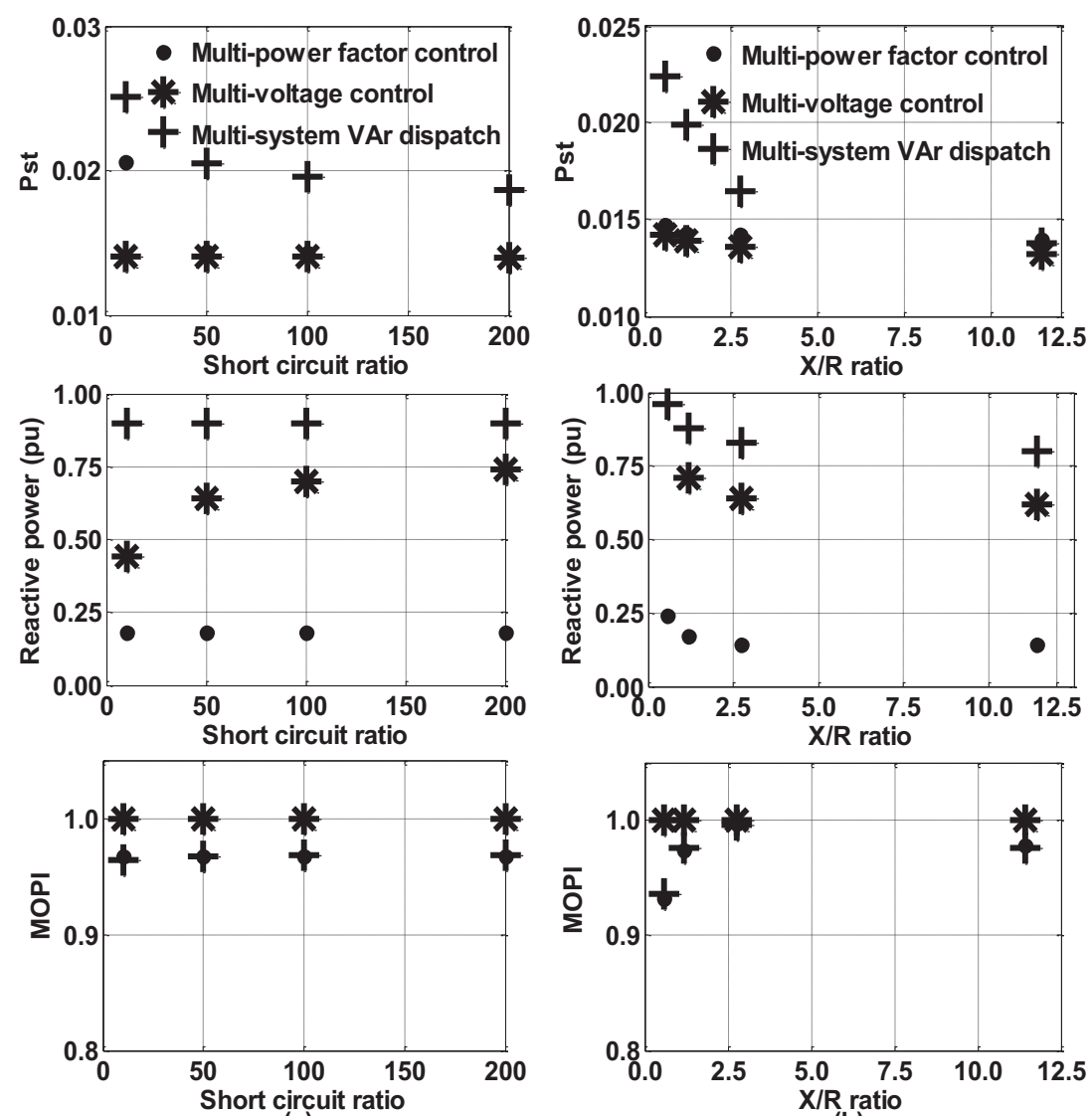

(a)

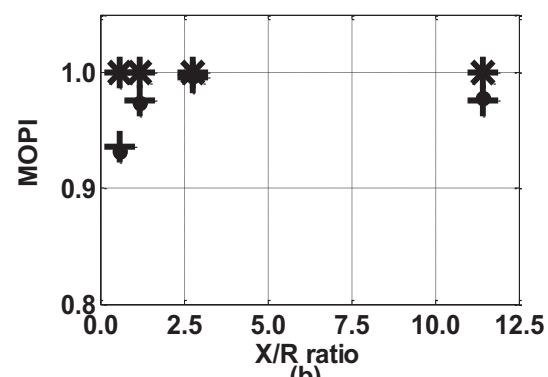

Figure 14: Performance comparison for multi-objective strategies with different network conditions (a) Short-circuit ratio (SCR) (b) $\mathrm{X} / \mathrm{R}$ ratios 